\title{
ОСОБЕННОСТИ РАЗВИТИЯ МОНО- И ПОЛИКУЛЬТУР БАКТЕРИЙ НА СТЕКЛЕ С РАЗЛИЧНЫМ РЕЛЬЕФОМ
}

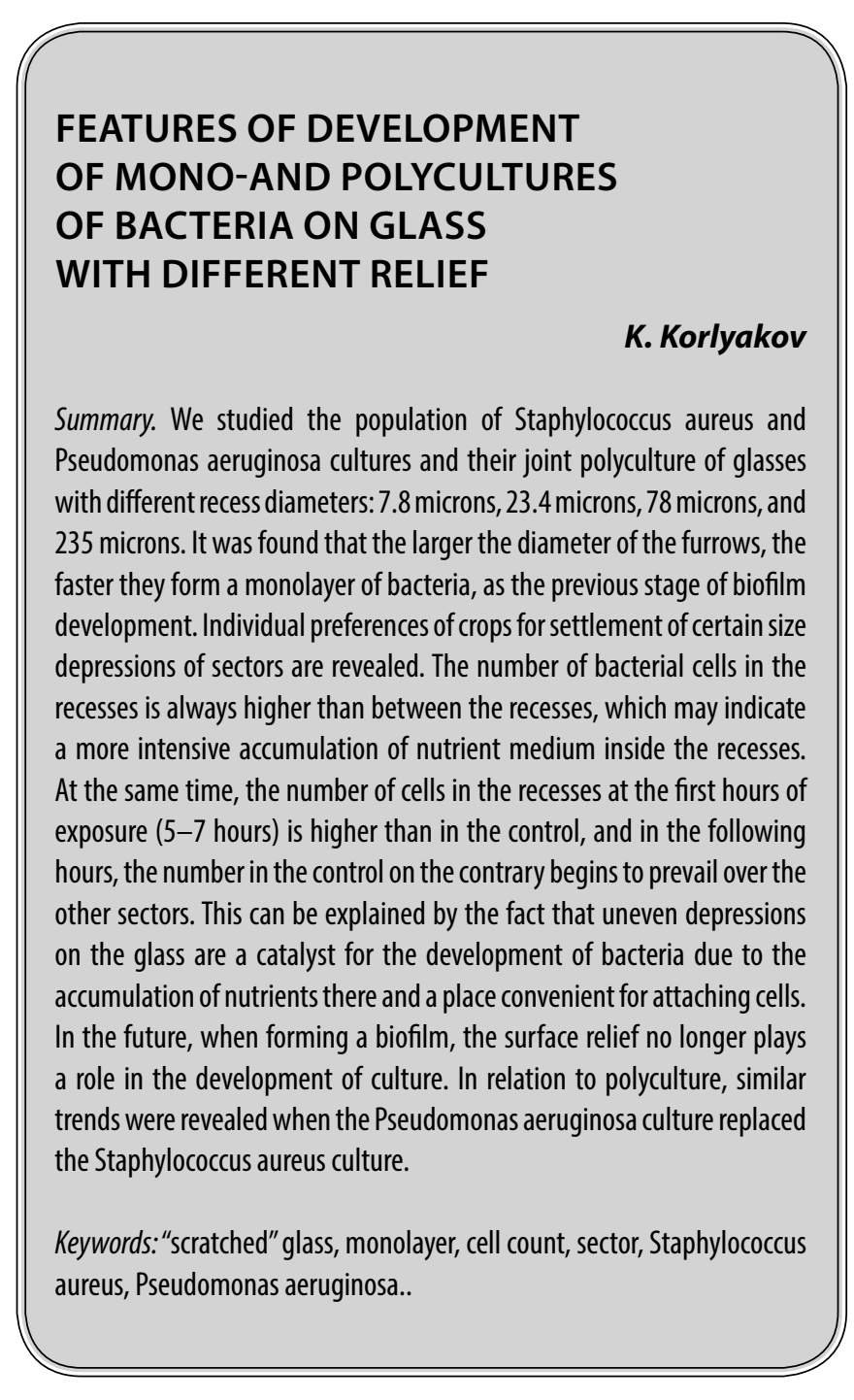

\section{Введение}

B опрос о матрицах и твердых ячейках для фиксации и культивирования бактерий, как и для эукариотических клеточных культур становится все более актуальным. В то же время структурные особенности твердого субстрата в виде стекла служащего основой для культивирования микроорганизмов до сих пор остаются мало изученными. Ранее нами были исследованы особенности адсорбции и развития микроорганизмов и гидробионтов на стекле с различными по размеру углублениями [1, 2]. Однако, первичное накопление ор-
Корляков Константин Александрович К.б.н., дочент, ФГБОУ ВО «Челябинский Государственный университет» korfish@mail.ru

Аннотация. Изучено заселение культурами Staphylococcus aureus и Pseudomonas aeruginosa и их совместной поликультурой стекол с различным диаметром углублений: 7.8 мкм, 23.4 мкм, 78 мкм и 235 мкм. Установлено, что чем больше диаметр борозд, тем быстрее в них формируется монослой бактерий, как предшествующая стадия развития биопленки. Выявлены индивидуальные предпочтения культур к заселению определенных по размеру углублений секторов. Численность клеток бактерий в углублениях всегда выше, чем между углублений, что может свидетельствовать 0 более интенсивном накоплении внутри углублений питательной среды. При этом численность клеток в углублениях на первых часах экспозиции (5-7 часов) выше, чем в контроле, а в последующие часы численность в контроле наоборот начинает превалировать над остальными секторами. Это может объясняться тем, что неровные углубления на стекле являются катализатором развития бактерий ввиду накопления там питательных веществ и местом удобным для прикрепления клеток. В дальнейшем, при формировании биопленки рельеф поверхности уже не играет значения в развитии культуры. В отношении поликультуры выявлены схожие тенденции при вытеснении культурой Pseudomonas aeruginosa культуры Staphylococcus aureus.

Ключевые слова: «царапанные» стекла, монослой, численность клеток, сектop, Staphylococcus aureus, Pseudomonas aeruginosa.

ганического вещества на неровной поверхности стекла, как правило обусловлено развитием бактериальных биопленок. Для чего необходимо изучение динамики развития клеток в различных углублениях — ячейках. И определение того, как те или иные изменения рельефа поверхности стекла блокируют или способствуют формированию колоний и биопленок, то есть влияют на все стадии развития бактериальных культур. Цель настоящей работы состояла в изучении особенностей роста бактериальных культур до формирования монослоя на секторах стекла с различными по размеру углублениями. 


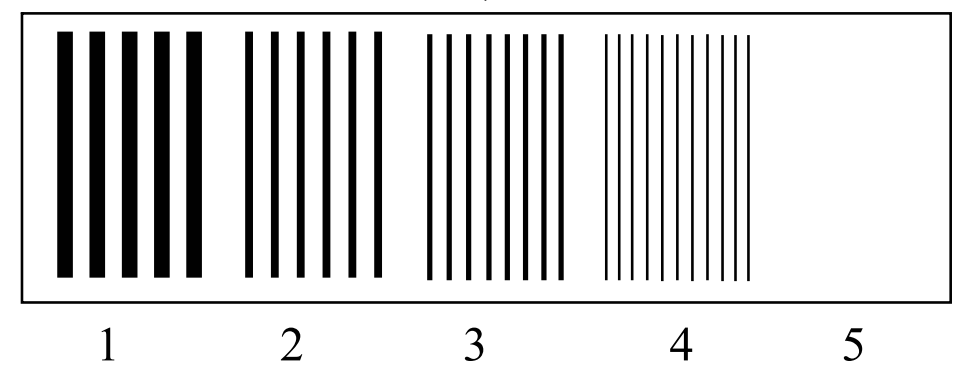

Рис. 1. Схема стекла с секторами: 1 сектор - ширина углублений 235 мкм, 2 сектор - ширина углублений 78 мкм, 3 сектор - ширина углублений 23.4 мкм, 4 сектор - ширина углублений 7.8 мкм, 5 сектор - контроль.

A

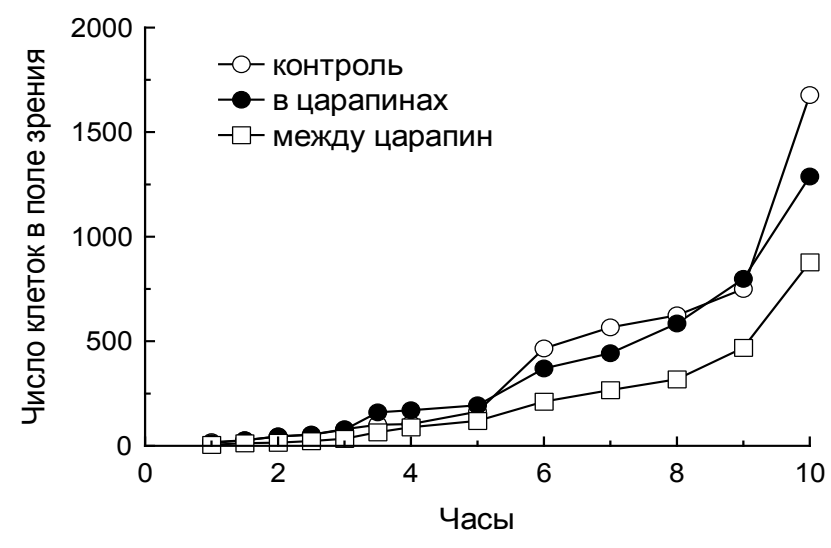

B

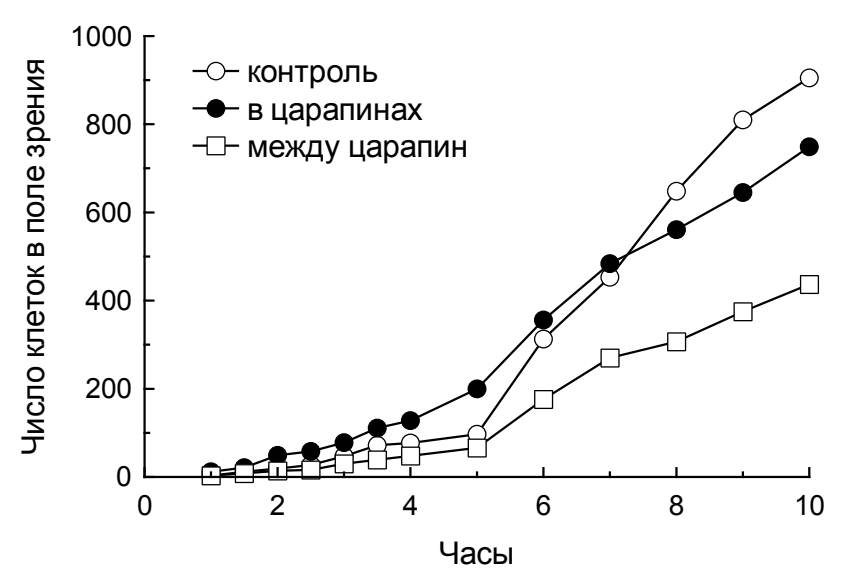

Рис. 2. Динамика роста среднего числа клеток монокультур по различным секторам в царапинах, между царапин и в контроле. A — Pseudomonas aeruginosa B - Staphylococcus aureus.

\section{Материал и методика}

Для исследований были использованы две культуры бактерий: Staphylococcus aureus штамм 25923 и Pseudomonas aeruginosa штамм 259212. Культуры выращивались по отдельности в виде монокультур и совместно в виде поликультуры. В качестве жидкой фазы для выращивания микроорганизмов использовали мясопептонный бульон. Культивирование осуществляли при температуре 370 С в одноразовых чашках Петри, содержащих по 20 мл питательной среды. Первые результаты в трехкратной повторности снимали через 1 , 1.5, 2, 2.5, 3, 3.5, 4, 5, 6, 7, 8, 9, 10, 24 часа. Предметные стекла были разделены на 5 секторов, на которых абразивной шкуркой были нанесены углубления различной толщины: 7.8 мкм, 23.4 мкм, 78 мкм и 235 мкм. Расстояния между углублениями составили соответственно: 78 мкм, 195 мкм, 312 мкм и 585 мкм. Сектора были расположены в порядке возрастания толщины углублений и увеличения удельных поверхностей (рис. 1).
Пятый сектор оставался необработанным (ровным) и использовался в качестве контроля. Стекла перед применением проходили дезинфекционную обработку (выдерживание в 96\% спирте) и стерилизацию (фломбирование).

Во всех случаях эффекты и различия считали статистически значимыми при $\mathrm{P} \leq 0.05$, незначимыми - при $\mathrm{P}>0.10$, промежуточные значения $(0.05 \leq \mathrm{P} \leq 0.10)$ обсуждали в качестве тенденций. Расчёты и графические построения выполнены в пакете KyPlot [3].

\section{Результаты исследования}

Средняя плотность клеток двух монокультур внутри углублений стекла была значительно выше, чем между углублениями (рис. 2).

В первые 5 часов у синегнойной палочки и 7 часов у золотистого стафиллакока численность клеток в углу- 
Таблица 1. Численность клеток Pseudomonas aeruginosa на различных секторах стекла: числитель внутри царапин, знаменатель - между царапинами.

\begin{tabular}{|c|c|c|c|c|c|c|}
\hline \multirow[b]{2}{*}{ Часы } & \multirow[b]{2}{*}{ Контроль } & \multicolumn{5}{|c|}{ Количество клеток на неровной поверхности } \\
\hline & & 1 сектор & 2 сектор & 3 сектор & 4 сектор & 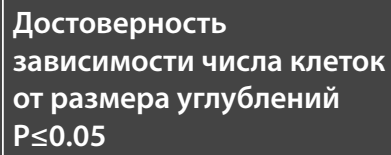 \\
\hline 1 & 18 & $9 / 4$ & $11 / 4$ & $16 / 7$ & $18 / 7$ & 0,0415 \\
\hline 1.5 & 26 & $27 / 14$ & $32 / 11$ & $27 / 12$ & $23 / 14$ & 0,2785 \\
\hline 2 & 45 & $38 / 12$ & $41 / 13$ & $46 / 16$ & $54 / 21$ & 0,0415 \\
\hline 2.5 & 53 & $52 / 23$ & $49 / 22$ & $54 / 22$ & $57 / 26$ & 0,1742 \\
\hline 3 & 80 & $86 / 30$ & $85 / 33$ & $41 / 36$ & $96 / 37$ & 1 \\
\hline 3.5 & 101 & $147 / 48$ & $154 / 54$ & $187 / 86$ & $155 / 72$ & 0,1742 \\
\hline 4 & 104 & $178 / 87$ & $156 / 91$ & $188 / 89$ & $160 / 90$ & 1 \\
\hline 5 & 163 & $193 / 116$ & 193/131 & $222 / 120$ & $171 / 109$ & 0,7179 \\
\hline 6 & 466 & $370 / 219$ & $392 / 219$ & $414 / 209$ & $306 / 204$ & 0,7290 \\
\hline 7 & 566 & $429 / 269$ & $457 / 255$ & $512 / 330$ & $376 / 214$ & 0,7290 \\
\hline 8 & 624 & $578 / 288$ & $575 / 316$ & $615 / 352$ & $572 / 316$ & 0,4969 \\
\hline 9 & 750 & $814 / 483$ & $791 / 477$ & $877 / 508$ & $711 / 408$ & 0,4969 \\
\hline 10 & 1677 & $1351 / 955$ & $1652 / 936$ & $1267 / 880$ & $885 / 742$ & 0,1742 \\
\hline 24 & \multicolumn{5}{|l|}{ монослой } & - \\
\hline
\end{tabular}

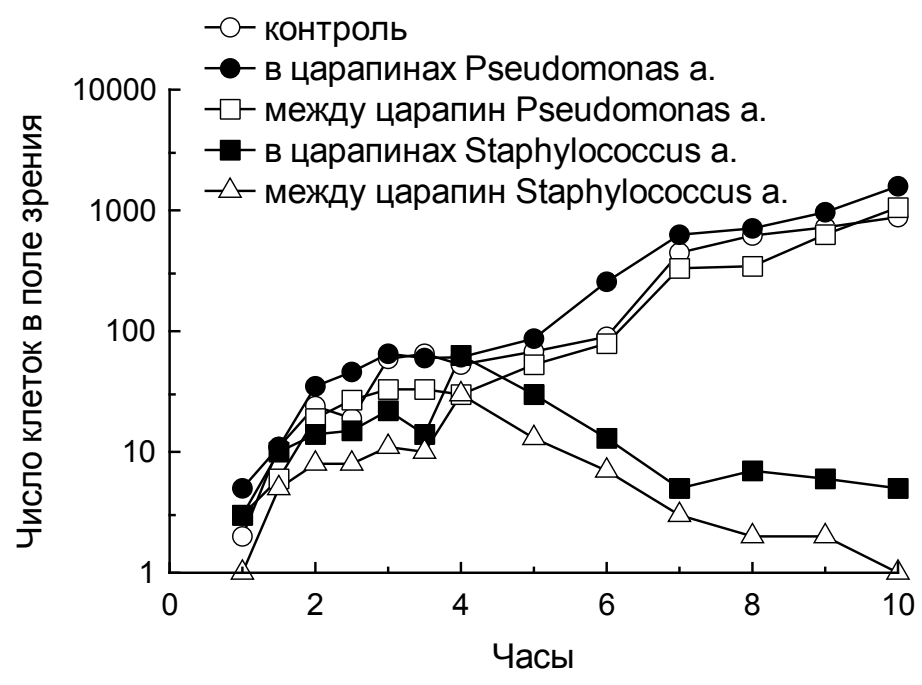

Рис. 3. Динамика роста среднего числа клеток поликультуры (Pseudomonas aeruginosa и Staphylococcus aureus) по четырем секторам в царапинах, между царапин и в контроле.

блениях была выше, чем в контроле. На последних часах численность клеток в контроле наоборот становилась выше, чем в углублениях. В поликультуре начиная с 5 часа культура Pseudomonas aeruginosa доминировала по численности подавляя Staphylococcus aureus (рис. 3).

При этом у обеих культур плотность клеток в углублениях также была выше, чем между углублениями. На 24 часу роста культуры Pseudomonas aeruginosa наблюдался монослой - сплошной одинарный по высоте слой клеток, охватывающий все поле зрения (табл. 1).

Однако, развитие монослоя клеток шло неравномерно на различных секторах. В культуре Pseudomonas aeruginosa на 10 часу наблюдался монослой в 5 полях зрения второго и первого секторов. Рост культуры Staphylococcus aureus был замедлен по сравнению 
Таблица 2. Численность клеток Staphylococcus aureus на различных секторах стекла: числитель внутри царапин, знаменатель - между царапинами.

\begin{tabular}{|c|c|c|c|c|c|c|}
\hline \multirow[b]{2}{*}{ Часы } & \multirow[b]{2}{*}{ Контроль } & \multicolumn{5}{|c|}{ Количество клеток на неровной поверхности } \\
\hline & & 1 сектор & 2 сектор & 3 сектор & 4 сектор & $\begin{array}{l}\text { Достоверность } \\
\text { зависимости числа клеток } \\
\text { от размера углублений } \\
\text { P } \leq 0.05\end{array}$ \\
\hline 1 & 3 & $8 / 2$ & $15 / 4$ & $16 / 4$ & $11 / 2$ & 0,4969 \\
\hline 1.5 & 12 & $22 / 9$ & $23 / 9$ & $19 / 7$ & $20 / 8$ & 0,4969 \\
\hline 2 & 19 & $39 / 16$ & $72 / 20$ & $46 / 12$ & $41 / 10$ & 1 \\
\hline 2.5 & 27 & $51 / 17$ & $77 / 17$ & $47 / 15$ & $57 / 14$ & 1 \\
\hline 3 & 47 & $69 / 26$ & $85 / 33$ & $81 / 25$ & $76 / 37$ & 1 \\
\hline 3.5 & 72 & $118 / 38$ & $107 / 48$ & $103 / 43$ & $117 / 28$ & 0,4969 \\
\hline 4 & 77 & $138 / 50$ & $123 / 51$ & $125 / 49$ & $126 / 42$ & 1 \\
\hline 5 & 97 & $202 / 65$ & $215 / 70$ & $212 / 61$ & $173 / 67$ & 0,4969 \\
\hline 6 & 313 & $375 / 189$ & $445 / 180$ & $364 / 196$ & $240 / 141$ & 0,1742 \\
\hline 7 & 453 & $552 / 301$ & $601 / 301$ & $447 / 264$ & $338 / 211$ & 0,1742 \\
\hline 8 & 648 & $656 / 352$ & $713 / 338$ & $507 / 299$ & $369 / 239$ & 0,1742 \\
\hline 9 & 810 & $707 / 386$ & $786 / 448$ & $611 / 353$ & $479 / 314$ & 0,1742 \\
\hline 10 & 905 & $829 / 454$ & $841 / 521$ & $711 / 409$ & $615 / 365$ & 0,1742 \\
\hline 24 & 1768 & $1487 / 885$ & 1696/798 & $1316 / 612$ & $1269 / 790$ & 0,1742 \\
\hline
\end{tabular}

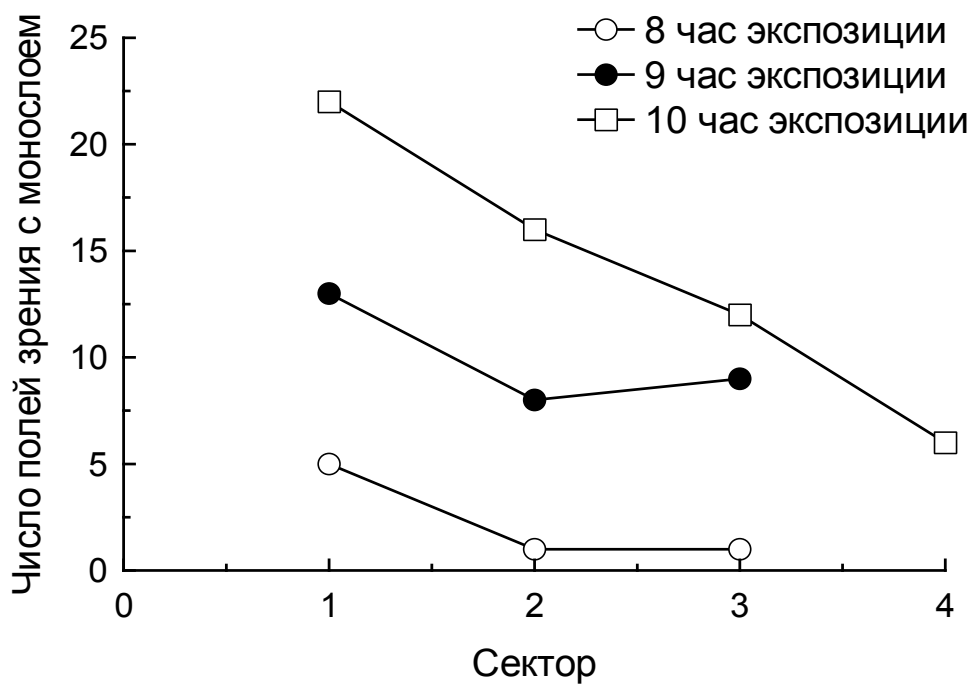

Рис. 4. Формирование бактериального монослоя (поликультуры Pseudomonas aeruginosa + Staphylococcus aureus) в полях зрения по часам на различных секторах.

с Pseudomonas aeruginosa и формирование монослоя не фиксировалось до последних стадий экспозиции 24 часа (табл. 2).

При смешении двух культур монослой также наблюдался у культуры Pseudomonas aeruginosa, но гораздо раньше - начиная с 8 часа экспозиции (рис. 4). На 8 часу монослой наблюдался на 7 полях зрения, на 9 часу на 30 полях зрения и на 10 часу - на 56 полях зрения (рис. 4).

При этом монослой клеток чаще наблюдался на секторах с наибольшим размерам углублений. Так на 1 секторе с углублениями диаметром 235 мкм число полей 
Таблица 3. Численность клеток Pseudomonas aeruginosa + Staphylococcus aureus на различных секторах стекла: числитель - внутри царапин, знаменатель - между царапинами.

\begin{tabular}{|c|c|c|c|c|c|c|}
\hline \multirow[b]{2}{*}{ Часы } & \multirow[b]{2}{*}{ Контроль } & \multicolumn{5}{|c|}{ Количество клеток на неровной поверхности } \\
\hline & & 1 сектор & 2 сектор & 3 сектор & 4 сектор & 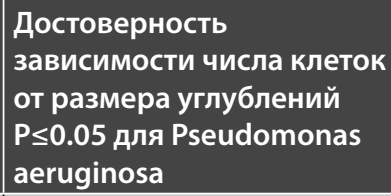 \\
\hline 1 & $\sqcap 2 \subset 2$ & $\sqcap 6 / 2$ с3/1 & $\Pi 6 / 3$ c4/1 & $\sqcap 6 / 3$ с3/1 & $\sqcap 4 / 2$ c3/1 & 0,1797 \\
\hline 1.5 & п11с6 & $\Pi 10 / 5$ c9/4 & п10/5 c9/3 & $\Pi 12 / 7$ с9/5 & $\Pi 13 / 6 \mathrm{c} 12 / 7$ & 0,0709 \\
\hline 2 & п24 с9 & п51/23 с16/9 & п36/14 с13/8 & $\sqcap 28 / 16$ с13/7 & $\sqcap 26 / 24$ с $15 / 10$ & 0,04154 \\
\hline 2.5 & п19с9 & $\sqcap 50 / 32$ c9/2 & п51/27 с15/7 & $\sqcap 43 / 25$ с $25 / 15$ & п39/25 с13/9 & 0,1742 \\
\hline 3 & п59 с23 & $\Pi 73 / 33$ с $18 / 10$ & п67/40 с28/11 & п54/28 с20/12 & п66/30 с22/11 & 0,1742 \\
\hline 3.5 & п65 с31 & п65/32 с14/8 & п70/35 с12/9 & п40/30 с10/11 & п65/36 с19/11 & 0,7179 \\
\hline 4 & $\sqcap 53$ с40 & п58/26 с60/28 & п67/34 с70/36 & п66/34 с67/36 & п54/28 с55/21 & 0,4969 \\
\hline 5 & п68 с11 & п117/75 с29/19 & п85/63 с40/12 & п74/40 с29/11 & п71/36 с24/12 & 0,0415 \\
\hline 6 & п90 с23 & п322/80 с10/7 & п390/95 с12/8 & п208/68 с10/8 & п109/74 с20/7 & 0,1742 \\
\hline 7 & п446 с8 & п819/428 с2/1 & п883/498 с7/3 & п485/272 с8/8 & п335/133 с4/1 & 0,1742 \\
\hline 8 & п619 с8 & п1030/588 с8/2 & п938/357 c7/1 & п452/238 с7/2 & п426/203 с6/1 & 0,0415 \\
\hline 9 & п724 с9 & п1324/889 c7/4 & п1474/1002 c7/2 & п530/291 с4/1 & п536/343 с7/1 & 0,4969 \\
\hline 10 & п882 C7 & п2105/1555 с5/1 & п1983/1390 c5/1 & п1220/724 c5/1 & п1045/567 c7/1 & 0,0415 \\
\hline 24 & \multicolumn{5}{|l|}{ монослой } & \\
\hline
\end{tabular}

Примечание: п — Pseudomonas aeruginosa, c — Staphylococcus aureus.

зрения с монослоем всегда превалировало по сравнению со 2 и 3 секторами с диаметрами борозд 78 и 23 мкм соответственно. А монослой на 4 секторе с углублениями диаметром 7.8 мкм образовывался только на 10 часу экспозиции (рис. 4) Следует отметить, что на контрольном секторе монослой не наблюдался до последних часов экспозиции - 24 часа, тогда как на секторах с неровным рельефом монослой начинал развиваться уже на 8-10 часах (смешанная культура). На последнем часе экспозиции монослой наблюдался на всех секторах, также, как в монокультуре Pseudomonas aeruginosa (табл. 3). Таким образом, можно констатировать опережающее развитие роста клеток в виде формирования монослоя, как первой стадии развития биопленки преимущественно на 1 и 2 секторах, отличающихся наибольшими размерами борозд (78-235 мкм). При этом на 10 часу экспозиции выявлена статистически значимая положительная корреляция между увеличением размера борозд и количеством полей зрения с монослоем в этих бороздах $(p=0.04)$. Тогда как на $8(p=0.22)$ и $9(\mathrm{p}=0.6)$ часах статистически достоверной связи выявлено не было. То есть, чем шире были углубления на стекле, тем быстрее там образовывался монослой формирующей в дальнейшем биопленку. Однако, в динамике роста клеток Pseudomonas aeruginosa в монои поликультуре наблюдались прямо противоположные тенденции освоения секторов. Так в монокультуре Pseudomonas aeruginosa в первые часы развития численность клеток достоверно $(p=0,04)$ увеличивалась с уменьшением размера углублений (табл. 1). В поликультуре плотность клеток Pseudomonas aeruginosa наоборот статистически значимо увеличивалась на 2, 5, 10 часах с увеличением размера углублений (табл. 3).

\section{Зак^ючение}

Таким образом, степень изменения рельефа поверхности стекла влияет на развитие моно- и поликультур микроорганизмов. Чем больше диаметр борозд, тем быстрее в них формируется монослой бактерий, как предшествующая стадия развития биопленки. Численность клеток бактерий в бороздах всегда выше, чем между борозд, что может свидетельствовать о более интенсивном накоплении там питательной среды. При этом численность клеток в углублениях на первых часах экспозиции (5-7 часов) выше, чем в контроле, а в последующие часы численность в контроле наоборот начинает превалировать над остальными секторами. Это может объясняться тем, что неровные углубления на стекле являются катализатором развития бактерий ввиду накопления там питательных веществ и местом удобным для прикрепления клеток. То есть являются энергетическим стимулятором развития для последующего развития колоний. В поликультуре микроорганизмов наблюдалась аналогичная картина при подавлении на 4-5 часах культурой синегнойной палочкой золотистого стафилококка. Также выявлены индивидуальные предпочтения различных культур к различным секторам. 


\section{ЛИТЕРАТУРА}

1. Корляков К.А., Арсентьева Н. Ю., Нохрин Д. Ю. Влияние сложности рельефа стекол на формирование монокультур микроорганизмов // Вестник уральской медицинской академической науки. 2011. № 4/1 (38). С. 35.

2. Корляков К.А., Нохрин Д. Ю., Арсентьева Н. Ю. Влияние неровностей рельефа стекол на формирование сообществ и монокультур обрастаний // Биология внутренних вод, 2015. № 1. С. 96-104.

3. Yoshioka K. KyPlot — a user-oriented tool for statistical data analysis and visualization // Computational Statistics. 2002. V. 17, № 3. P. $425-437$.

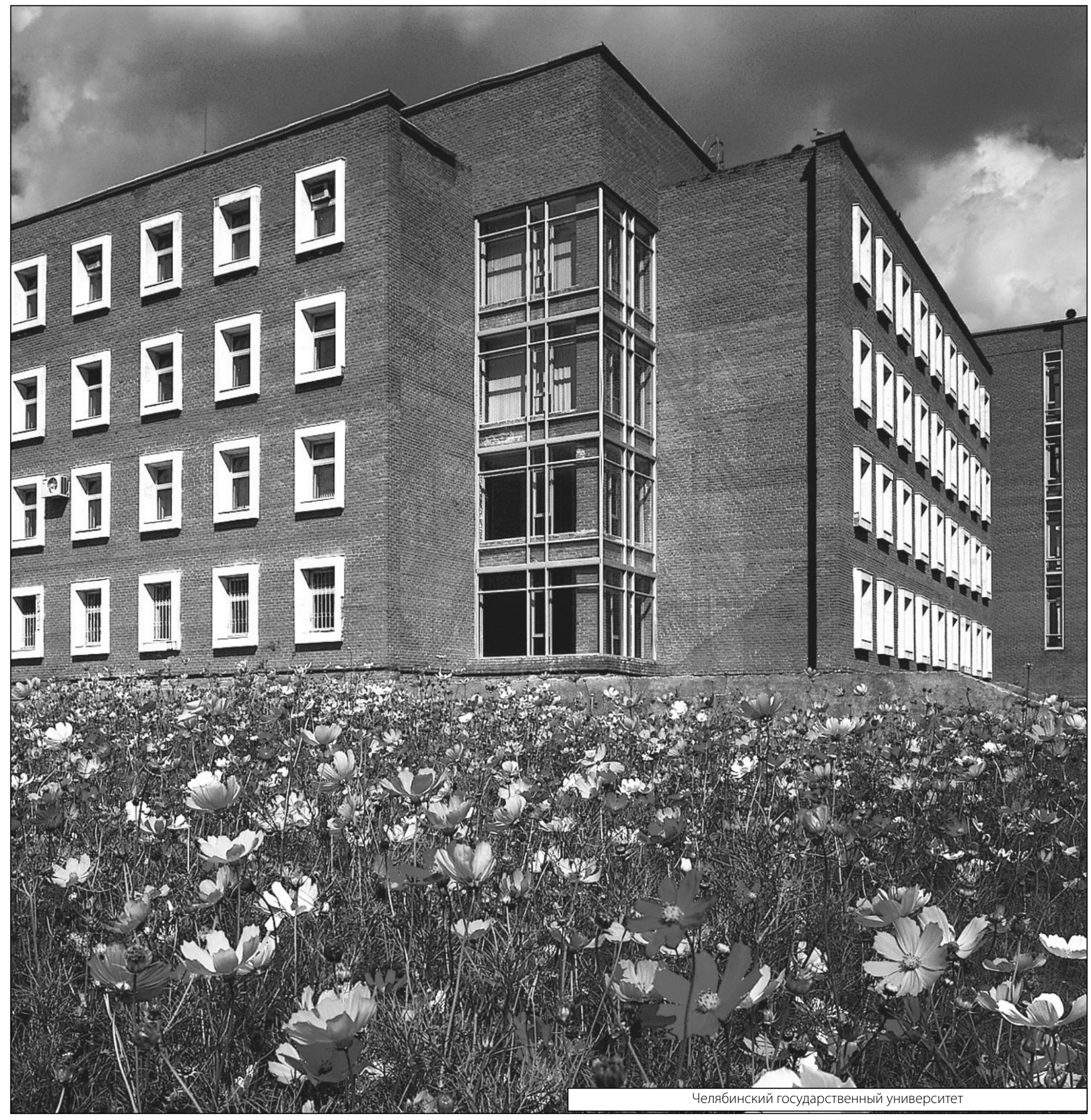

